Erratum to Vol. 37, No. 3, March 2008

\title{
Ambient Temperature Ultrasonic Bonding of Si-Dice Using Sn-3.5wt.\%Ag
}

\author{
JUNG-MO KIM, ${ }^{1,2}$ JAE-PIL JUNG, ${ }^{3,5}$ Y. NORMAN ZHOU, ${ }^{2}$ \\ and JONG-HYEONG KIM ${ }^{4}$ \\ 1.-University of Seoul, Seoul, Republic of Korea. 2.-Department of Mech. Eng., University of \\ Waterloo, Waterloo, Canada N2L 3G1. 3.-Department of Mater. Sci. and Eng., University of \\ Seoul, Seoul 130-743, Republic of Korea. 4.-Seoul Nat'l University of Technology, Seoul 139-743, \\ Republic of Korea. 5.—e-mail: jpjung@uos.ac.kr
}

\section{Erratum to Journal of ELECTRONIC MATERIALS DOI 10.1007/s11664-007-0341-z}

In this article, the last author's name was written incorrectly. The correct author's name is Jong-Hyeong Kim. 